\title{
Insight, psychosis and aggressive behaviour in mania
}

\author{
Itxaso González-Ortega* \\ Fernando Mosquera ** \\ Enrique Echeburúa* \\ Ana González-Pinto** \\ * University of Basque Country, \\ Department of Clinical Psychology, \\ San Sebastián, CIBERSAM
}

** Santiago Apóstol Hospital, Department of Psychiatry, Vitoria, CIBERSAM

SPAIN

\begin{abstract}
Background and Objectives: Aggressiveness is a common component of manic symptoms. The aim of this study was to determine the clinical characteristics associated with aggressive behaviour in bipolar patients with acute manic episodes.

Methods: A study was carried out with 173 patients who met the DSM-IV criteria for manic or mixed bipolar disorder. Clinical and demographic variables were evaluated using the Positive and Negative Symptoms Scale (PANSS), the Young Mania Rating Scale (YMRS), the Brief Psychiatric Rating Scale (BPRS), and the Hamilton Depression Rating Scale (HDRS). Significance and independence of relevant variables were tested with regression models.

Results: Forty percent of patients displayed aggressive behaviour. Involuntary nature of admission, positive psychotic symptoms and lack of insight were predictors of aggressive behaviour in manic patients.

Conclusions: Aggressive behaviour during acute manic episodes appears to be related with the severity of the psychopathology, and particularly positive psychotic symptoms, involuntary admissions and lack of insight.
\end{abstract}

Received: 21 April 2009

Revised: 24 September 2009

Accepted: 20 October 2009 


\section{Background}

Violent behaviour is relatively common in bipolar disorder and usually occurs during acute manic episodes ${ }^{1-5}$. The relationship between violence and psychotic symptoms has been widely described ${ }^{6-14}$. This is consistent with other psychiatric conditions in which psychotic symptoms are also correlated with an increased risk of violence ${ }^{15-19}$. Some studies have focused on the presence of mood congruent/incongruent psychotic symptoms in mania ${ }^{13,20-22}$. It has been observed that manic patients with incongruent psychotic symptoms score higher for agitated, aggressive behaviour ${ }^{13,23}$.

Patients with acute mania often require hospitalization, as their symptoms (grandiosity, impulsiveness, agitation, psychosis) may have substantial legal, penal, civil, work-related and social repercussions. Various studies have described how manic patients display high levels of violence during the early weeks of hospitalization and exhibit violent behaviour in the community in the two weeks prior to admission ${ }^{8,24-26}$. Their rate of violence tends to decrease following the immediate post-admission period on receiving effective interventions and treatment from hospital staff ${ }^{27-29}$. This is consistent with the view that the state or phase of the illness, in terms of acuteness or remission, is a useful predictor of violence ${ }^{30}$.

One factor related with aggressiveness in manic patient is lack of insight. In fact, it has been shown that aggressiveness and lack of insight are grouped together in the same dimension $^{31}$.

The aim of this study was to determine the clinical and sociodemographic characteristics associated with aggressive behaviour in a sample of bipolar patients with acute manic episodes.

\section{Patients and methods}

\section{Subjects}

A study was carried out on patients admitted to Santiago Hospital between 1997 and 2000. Patients who provided informed consent were included in the study. The sample included 173 subjects aged between 16 and 82 years.

Participants had to meet the DSM-IV criteria for type I manic or mixed bipolar disorder. Subjects with mental retardation, cerebral organic disorders or with a diagnosis of substance-induced mood disorder were excluded.

\section{Evaluation methods}

Diagnosis was determined using the Structured Clinical Interview for DSM-IV Axis I Disorders (SCID-I) ${ }^{32}$. The relevant clinical and demographic variables were gathered at the time of admission (at the 48 first hours) using an extensive protocol including age, duration of illness, inappropriate use of alcohol and drugs, suicide attempts and psychotic symptoms, as evaluated with the Positive and Negative Symptoms Scale ${ }^{33}$ (PANSS: P, N and PG), the Brief Psychiatric Rating Scale ${ }^{34}$ (BPRS) and the Schneider's first rank symptoms ${ }^{35}$. Manic and depressive symptoms were evaluated with the Young Mania Rating Scale $^{36}$ (YMRS), the Hamilton Depression Rating Scale ${ }^{37}$ (HDRS-21).

Both the aggressive behavior and degree of insight were assessed with the items 9 (aggressive behaviour) and 11 (insight) of YMRS respectively. Aggressiveness was defined as a score $\geq 4$ on item 9 (aggressive behaviour) of the YMRS. The insight was defined as a score $\geq 2$ on item 11 (insight) of YMRS. Both variables were treated as dico- 
tomic variables in bivariate analysis to know the description and presence or not of this variable. On the other hand, insight and aggressiveness have been considered as continuous variables to know the severity of these phenomena and with predictive purpose on the linear regression model.

\section{Statistical analysis}

The relationships between aggressive behaviour and the clinical and demographic data were analyzed using the Mann-Whitney $U$ test for two independent samples, Student's t-test for equality of means and Pearson's chi-square test. Significance and independence of the relevant variables were tested with a linear regression model. We performed a linear regression with aggressiveness as the dependent variable, and all the independent variables with $\mathrm{p}<0.01$ in bivariate analysis. SPSS for Windows, version 15.0.1, was used for the analyses.

\section{Results}

\section{Demographic and clinical data}

One hundred and seventy-three patients participated in the study, including 86 women and 87 men. The mean age of the patients was 35.06 years $( \pm 12.34)$. From this sample, $78.6 \%$ (136) met the DSM-IV criteria for pure mania and $21.4 \%$ (37) for mixed bipolar episodes. Admission was voluntary for $63.7 \%$ of the sample and involuntary for $36.3 \%$. The clinical and demographic characteristics of the sample are provided in Table 1.

Table 1

Demographic and clinical variables for the sample

\begin{tabular}{|c|c|c|c|c|}
\hline & & $\mathrm{N}$ & \multicolumn{2}{|c|}{ Percentage } \\
\hline \multirow{5}{*}{ Marital status } & Single & 112 & \multicolumn{2}{|c|}{64.7} \\
\hline & Married & 46 & \multicolumn{2}{|c|}{26.6} \\
\hline & Other & 15 & \multicolumn{2}{|c|}{8.7} \\
\hline & Total & 173 & \multicolumn{2}{|c|}{100} \\
\hline & & $\mathrm{N}$ & Mean & SD \\
\hline \multicolumn{2}{|l|}{ Years from first symptoms } & 173 & 8.59 & 9.23 \\
\hline \multicolumn{2}{|l|}{ Years from first treatment } & 173 & 7.06 & 8.19 \\
\hline \multicolumn{2}{|l|}{ Age on admission } & 173 & 35.06 & 12.34 \\
\hline \multicolumn{2}{|l|}{ Age at onset } & 173 & 26.47 & 10.64 \\
\hline \multicolumn{2}{|l|}{$\mathrm{N}^{\circ}$ of days hospitalized } & 173 & 20.92 & 11.53 \\
\hline \multicolumn{2}{|l|}{$\mathrm{N}^{\mathrm{o}}$ of episodes } & 173 & 4.90 & 5.20 \\
\hline \multicolumn{2}{|l|}{$\mathrm{N}^{\mathrm{o}}$ of Schneider symptoms } & 173 & 0.43 & 1.01 \\
\hline \multicolumn{2}{|l|}{ "Dysphoric" dimension } & 173 & 9.46 & 4.69 \\
\hline
\end{tabular}

Of the 173 patients included in the study, $69(40 \%)$ displayed aggressive behaviour. Curiously, gender was not a predictive factor of aggressive behaviour; there was no association between aggressiveness and male sex $\left(\chi^{2}=1.05 ; \mathrm{p}=0.30\right)$.
The scores on the positive and general PANSS subscales were higher for aggressive patients: PANSS P $(z=-2.74 ; p<0.01)$ and PANSS PG $(\mathrm{z}=-3.54 ; \mathrm{p}<0.01)$. The BPRS scale also showed higher scores in aggressive patients $(\mathrm{z}=3,430 ; \mathrm{p}<0.01)$. Statisti- 
cally significant differences were found between aggressive and non-aggressive patients on the YMRS scale $(z=5.96 ; p<0.01)$. Psychotic symptoms evaluated with Schneider's number of symptoms was also associated with aggressive behaviour $(\mathrm{z}=-2.03 ; \mathrm{p}<0.05)$.

Patients with aggressive behaviour had a significantly higher mean score than non-aggressive patients on the 'dysphoric' dimension $(z=-9.66 ; p<0.001)$, with high scores on the following items from the Young scale: 'irritability' ( $\mathrm{z}=-6.18$; $\mathrm{p}<0.01)$; 'abnormal behaviour' $(z=-11.62 ; p<0.01)$ and 'insight' $(\mathrm{z}=-4.07 ; \mathrm{p}<0.01)$. Furthermore, those with aggressive behaviour were more frequently hospitalized involuntarily $\left(\chi^{2}=\right.$ 16.1; $\mathrm{p}<0.01)$.
Prior suicide attempts were recorded in $24.4 \%$ of patients, but no relationship between aggressive behaviour and suicidal behaviour was found $\left(\chi^{2}=0.26 ; \mathrm{p}=0.61\right)$. While $30.1 \%$ and $24.4 \%$ of patients had histories of alcohol and cannabis abuse respectively, with $14.5 \%$ reporting use of other drugs and $69.6 \%$ having a tobacco addiction, we did not find any association between substance abuse and aggressiveness (Table 2).

Using linear regression models to find those factors independently associated with aggressiveness, we found that involuntary admission $(\mathrm{t}=-2.91 ; \mathrm{p}<0.01)$, positive psychotic symptoms $(\mathrm{t}=2.99 ; \mathrm{p}<0.01)$ and lack of insight $(\mathrm{t}=3.33$; $\mathrm{p}<0.01)$ all predicted aggressive behaviour in manic patients (Table 3).

Table 2

Clinical variables for aggressive and non-aggressive patients

\begin{tabular}{lcccccccc} 
& \multicolumn{7}{c}{$\begin{array}{c}\text { Aggressive } \\
\text { patients }\end{array}$} & \multicolumn{2}{c}{$\begin{array}{c}\text { Non aggressive } \\
\text { patients }\end{array}$} \\
\hline & $\mathrm{N}$ & $\%$ & $\mathrm{n}$ & $\%$ & $\mathrm{n}$ & $\%$ & $\chi^{2}$ & $\mathrm{p}$ \\
\hline Male sex & 87 & 50.3 & 49 & 56.3 & 38 & 43.7 & 1.05 & 0.30 \\
\hline Substance abuse & & & & & & & & \\
\hline Tobacco adiction & 121 & 69.9 & 70 & 57.9 & 51 & 42.1 & 0.86 & 0.35 \\
Cannabis abuse & 42 & 24.2 & 19 & 45.2 & 23 & 54.7 & 0.66 & 0.41 \\
Other substances & 25 & 14.4 & 10 & 40 & 15 & 60 & 0.0002 & 0.99 \\
Alcohol abuse & 52 & 30 & 24 & 57.1 & 28 & 42.9 & 1.22 & 0.27 \\
\hline Suicide attempts & 42 & 24.2 & 18 & 42.9 & 24 & 57.1 & 0.26 & 0.61 \\
\hline Dysphoric dimension & 60 & 34.6 & 24 & 40 & 36 & 60 & 1.05 & 0.30 \\
\hline
\end{tabular}

Table 3

Linear regression

\begin{tabular}{|c|c|c|c|c|c|c|}
\hline & \multicolumn{6}{|c|}{$95 \% \mathrm{CI}$ for $\mathrm{B}$} \\
\hline & \multirow[t]{2}{*}{$\beta$} & \multirow[t]{2}{*}{ B } & & & \multirow[t]{2}{*}{$\mathrm{t}$} & \multirow[t]{2}{*}{$\mathrm{p}$} \\
\hline & & & Min. & Max. & & \\
\hline Voluntary nature of admission & -0.21 & -0.97 & -1.62 & -0.32 & -2.96 & 0.004 \\
\hline Insight according to YMRS & 0.24 & 0.37 & 0.14 & 0.59 & 3.28 & 0.001 \\
\hline PANSS P & 0.21 & 0.07 & 0.02 & 0.11 & 3.02 & 0.003 \\
\hline
\end{tabular}

Dependent variable: Abnormal, aggressive behaviour. 


\section{Discussion}

The main finding of this investigation is that aggressiveness in bipolar patients during acute episodes depends on the severity of the episode and the degree of awareness of illness. A lack of awareness of illness, positive symptoms and the involuntary nature of the admission are the factors that predict aggressiveness. While some of these findings have already been described, no study has yet taken all these factors into account simultaneously and controlled the independence of these variables. It is important to differentiate between aggressiveness that occurs during acute illness and that which arises outside of this context, due to other factors that may explain aggressiveness in human beings. We believe that this distinction would contribute for removing the stigma associated with mental illness and particularly with bipolar disorder. The violence they show is not inherent but rather due to decompensation ${ }^{1-5}$.

Aggressive behaviour is principally related with psychopathology. Severity of symptoms and lack of insight are factors associated with aggressiveness in mania. This results in involuntary admission that, in turn, has been associated with a greater degree of aggression in patients with acute mania. More specifically, aggressiveness during mania appears to be clearly related to positive psychotic symptoms (auditory hallucinations, conceptual disorganization, and paranoid delusions). The scores on the Positive (PANSS P) and General (PANSS PG) Symptoms Scales, as well as the high scores on Schneider's number of psychotic symptoms criteria, indicate that severity of psychotic symptoms is a useful predictor of aggressive behaviour. Our results are in line with other studies that describe a relationship between aggressiveness and the presence of psychotic symptoms in manic patients ${ }^{6-13,23}$.

To date, no consensus has existed with regard to the association between insight and aggressiveness. Many studies have demonstrated a significant relationship between insight and positive symptoms, both in bipolar disorder and in other mental disorders ${ }^{14,37-43}$. However, other authors conclude that reduced insight is not associated with high levels of psychopathology 44, 45. Our research, which represents all manic population in psychiatric treatment in a health catchment area, now establishes a clear association between lack of insight and violence. An earlier study carried out with another patients sample found that aggressiveness and lack of insight were located in the same dimen$\operatorname{sion}^{31}$. Although participating in the study with informed consent is indicative of some degree of insight in all manic patients, there are relevant differences in this variable among the manic patients with or without aggressive behaviour.

Outbursts or aggressive states are thus associated with rapidly executed, impulsive acts of unexpected violence, occurring in response to minimal provocation or, on occasion, for no discernable reason. During these outbursts, a great deal of pathological tension is relieved. The tendency to engage in risky and aggressive behaviours is a core feature of the manic episodes of bipolar disorder because manic patients clearly show defects in decision making, which are strongly related to their lack of insight ${ }^{46}$. A recent meta-analytical investigation demonstrated that in bipolar disorder, insight improves after acute manic episodes, suggesting that degree of insight depends on the phase of the bipolar disorder ${ }^{47}$.

It comes as no surprise that hospital admission is often involuntary during the acu- 
te phase of the illness in those patients with the most severe symptoms ${ }^{2}$.

As demonstrated in other studies, we found that aggressive behaviour is associated with the involuntary nature of admission in manic patients. Involuntary admission is also significantly associated with a greater degree of aggression and lesser insight during acute mania, a finding which is also backed up by other studies ${ }^{14,38-43}$.

Despite the fact that men are more violent than women in the general population ${ }^{48}$, gender was not associated with aggressive behaviour in our sample of manic patients, in line with other studies $25,48-52$. For this reason, aggressiveness may be an indicator of mental state during acute mania in bipolar disorder. Taking this into account may help to diminish stigma in patients with bipolar disorder.

Among the limitations of this study, we must mention that "aggressiveness" and "lack of insight" have been measured with one single item on the YMRS and this may not be sufficient or sensitive enough to capture the whole meaning of both concepts.

\section{References}

1. Yesavage JA. Bipolar illness: correlates of dangerous inpatient behaviour. Br J Psychiatry 1983; 143: 554-557.

2. Ghaemi SN, Stoll AL, Pope HG. Lack of insight in bipolar disorder: The acute manic episode. J Nerv Ment Dis 1995; 183: 464-467.

3. Quirk A, Lelliot P. What do we know about life on acute psychiatric wards in the UK? A review of the research evidence. Social Sci Med 2001; 53: 1565-1574.

4. Cassidy F, Ahearn EP, Carrol BJ. Symptom profile consistency in recurrent manic episodes. Comprehens Psychiatr 2002; 43: 179-181.
5. Sato T, Bottlender R, Sievas M, Schoroter A, Hecht S, Mollr HJ. Long-term inter-episode stability of syndromes underlying mania. Acta Psychiatr Scand 2003; 108: 310-313.

6. Carlson GA, Goodwin, FK. The stages of mania: a longitudianl analysis of the manic episode. Arch Gen Psychiatry 1978; 28: 221-228.

7. Tardiff K. Emergency management of violent patients. New Trends Exp Clin Psychiatr 1999; 15: 145-149.

8. Feldmann TB. Bipolar disorder and violence. Psychiatr Q 2001; 72 (2): 119-129.

9. Swann AC, Janicak PL, Calabrese JR, Bowden CL, Dilsaver SC, Morris DD, et al. Structure of mania: depressive, irritable, and psychotic clusters with different retrospectively-assessed course patterns of illness in randomized clinical trial participants. J Affect Disord 2001; 67: 123-132.

10. Sato T, Bottlender R, Kleindienst N, Möller HJ. Syndromes and Phenomenological Subtypes Underlying Acute Mania: A Factor Analytic Study of 576 Manic Patients. Am J Psychiatry 2002; 159: 968-974.

11. Vieta E, Brugué E, Goikolea JM, Sánchez-Moreno J, Reinares M, Comes M, et al. Acute and continuation risperidone monotherapy in mania. Hum Psychopharmacol 2004; 19: 41-45.

12. Haro JM, Edgell ET, Novick D, Alonso J, Kennedy L, Jones PB, et al. SOHO advisory board. Effectiveness of antipsychotic treatment for schizophrenia: 6-month results of the Pan-European Schizophrenia Outpatient Health Outcomes (SOHO) study. Acta Psychiatr Scand 2005; 111 : 220-231.

13. Azorin JM, Akiskal H, Hantouche E. The mood-instability hypothesis in the origin of mood-congruent versus mood-incongruent psychotic distinction in mania: validation in a French National Study of 1090 patients. J Affect Disord 2006; 96: 215-223.

14. Schuepbach D, Goetz I, Boeker H, Hell D. Voluntary vs. involuntary hospital admission in acute mania of bipolar disorder: Results from the Swiss sample of the EMBLEM study. J Affect Disord 2006; 90: 57-61.

15. Tardiff K, Sweillam A. Assault, suicide and mental illnes. Arch Gen Psychiatry 1980; 37: 164-169.

16. Junginger J, Parks-Levy J, McGuire L. Delusions and symptom-consistent violence. Psychiatr Serv 1998; 49: $218-220$.

17. Link B, Andrews H, Cullen FT. The violent and illegal behaviour of mental patients reconsidered. Am Sociological Rev 1992; 57: 275-292. 
18. McNiel DE, Binder RL. The relationship between acute psychiatric symptoms, diagnosis and short-term risk of violence. Hosp Com Psychiatry 1994; 45: 133-137.

19. Nijman HLI. A model of aggression in psychiatric hospitals. Acta Psychiatr Scand 2002; 106: 142-143.

20. Tohen M, Tsuang MT, Goodwin DC. Prediction of outcome in mania by mood-congruent or mood incongruent psychotic features. Am J Psychiatry 1992; 149: 1580-1584.

21. Fenning S, Bromet EJ, Karant MT, Ram R, Jandorf L. Mood- congruent versus mood-incongruent psychotic symptoms in first-admission patients with affective disorder. J Affect Disord 1996; 37: 23-29.

22. Coryell W, Leon AC, Turvey C, Akiskal H, Mueller $\mathrm{T}$, Endicott J. The significance of psychotic features in manic episodes. A report from the NIMH collaborative study. J Affect Disord 2001; 67: 79-88.

23. Toni C, Perugi G, Mata B, Maremmani I, Akiskal HS. Is mood-congruent manic psychosis a distinct subtype?. Eur Arch Psychiatry Clin Neurosci 2001; 251: 12-17.

24. McNiel DE, Binder RL, Greenfield TK. Predictors of violence in civilly committed acute psychiatric patients. Am J Psychiatry 1988; 145: 965-970.

25. Barlow K, Grenyer B, Ilkiw-Lavalle O. Prevalence and precipitants of aggression in psychiatric units. Aust NZJ Psychiatry 2000; 34: 967-974.

26. El-Badri SM, Mellsop G. Aggressive behaviour in acute general adult psychiatric unit. Psychiatr Bulletin 2006; 30: 166-168.

27. Heilbrun K, Hart SD, Hare RD, Gustaffson D, Nunez C, White AJ. Inpatient and post discharge aggression in mentally disordered offenders: The role of psychopathy. J Interpers Viol 1998; 13: 514-527.

28. McNiel DE, Binder RL. Relationship between preadmission threats and later violent behaviour by acute psychiatric inpatients. Hosp Com Psychiatry 1989; 40: 605-608.

29. Doyle M, Dolan M, McGovern J. The validity of North American risk assessment tools in predicting in-patients violent behaviour in Englang. Legal Criminol Psych 2002; 7: 141-154.

30. Davis S. Violence by psychiatric inpatients: a review. Hosp Community Psychiatr 199; 42: 585-590.

31. González-Pinto A, Ballesteros J, Aldama A, Pérez de Heredia JL, Gutiérrez M, Mosquera F. Principal components of mania. J Affect Disord 2003; 76: 95-102.

32. First MB, Gibbon M, Spitzer RL, Williams JBW. User's guide for the Structured Clinical Diagnostic Inter- view for DSM-IV Axis I Disorders (SCID-I). Washington, DC: American Psychiatric Press; 1997.

33. Kay SR, Fiszbein A, Opler LA. The positive and Negative Syndrome Scale (PANSS) for Schizofrenia. Schizophr Bull 1987; 13: 261-276.

34. Overall JE, Gorham DR. The Brief Psychiatric Rating Scale. Psychol Rep 1962; 10: 799-812.

35. Schneider K. Patopsicología Clínica. Madrid: Paz Montalvo; 1975.

36. Young RC, Bigss JT, Ziegler VE, Meyer DA. A rating scale for mania: Reability, validity and sensitivity. Br J Psychiatr 1978; 133: 429-435.

37. Hamilton MA. Rating scale for depression. J Neurol Psychiatr 1960; 23: 56-62.

38. David AS, Buchanan A, Reed A, Almeida O. The assessment of insight in psychosis. Br J Psychiatry 1992; 161: 599-602.

39. Kemp RA, Lambert TJ. Insight in schizophrenia and its relationship to psychopathology. Schizophr Res 1995; 18: 21-28.

40. Collins AA, Remington GJ, Coulter K, Birkett K. Insight, neurocognitive function and symptom clusters in chronic schizophrenia. Schizophr Res 1997; 27: 37-44.

41. Swartz MS, Swanson JW, Hiday VA, Borum R, Wagner HR, Burns BJ. Violence and severe mental illness: the effects of substance abuse and nonadherence to medication. Am J Psychiatry 1998; 155: 226-231.

42. Arango C, Calcedo A, González T, Calcedo A. Violence in inpatients with schizophrenia: a prospective study. Schizophr Bull 1999; 25: 493-503.

43. Raja M, Azzoni A. Hostility and violence of acute psychiatric inpatients. Clin Pract Epidemol Ment Health 2005; $1: 11$.

44. Lysaker P, Bell M, Milstein R, Bryson G, BeamGoulet J. Insight and psychosocial treatment compliance in schizophrenia. Psychiatry 1994; 57 (4): 307-315.

45. Smith TE, Hull JW, Santos L. The relationship between symptoms and insight in schizophrenia: A longitudinal perspective. Schizophr Res 1998; 33: 63-67.

46. Adida M, Clark L, Pomietto P, Kaladjian A, Besnier $\mathrm{N}$, Azorin JM, et al. Lack of insight may predict impaired decision making in manic patients. Bipolar Disord 2008; 10 (7): 829-837.

47. Ghaemi SN, Rosenquist KJ. Is insight in mania state-dependent? A meta-analysis. J Nerv Ment Dis 2004; 192: 771-775. 
48. Krakowski M, Czobor P. Gender differences in violent behaviours: relationship to clinical symptoms and psychosocial factors. Am J Psychiatry 2004; 161: 459-465.

49. Binder RL, McNiel DE. The relationship between gender and violent behavior by acutely disturbed psychiatric patients. J Clin Psychiatry 1990; 51:110-114.

50. Kho K, Sensky T, Mortimer A, Corcos C. Prospective study into factors associated with aggressive incidents in psychiatric acute admission wards. Br J Psychiatry 1998; 172: 38-43.

51. Lam JN, McNiel DE, Binder RL. The relationship between patients' gender and violence leading to staff injuries. Psychiatr Serv 2000; 51: 1167-1170.
52. Mellesdal L. Aggression on a psychiatric acute ward: a three-year prospective study. Psychol Rep 2003; 92: 1229-1248.

Address for correspondence:

University of Basque Country

Avda. de Tolosa, 70

20018 San Sebastián (SPAIN)

Tel.: +34-943-018-329

Fax: +34-943-015-670

E-mail: itxigonzalezortega@hotmail.com 